\title{
Effects of Superoxide Dismutase and Catalase on Endotoxin Shock in Rats
}

\author{
Toshikazu Yoshikawa,* Masashi Murakami, Osamu Seto, \\ Yoriko Kakimi, Toshiki Takemura, Tohru Tanigawa, \\ Shigeru Sugrno, and Motoharu Kondo \\ First Department of Medicine, Kyoto Prefectural University \\ of Medicine, Kyoto 602, Japan
}

(Received January 21, 1986)

\begin{abstract}
Summary The effects of superoxide dismutase (SOD) and catalase on endotoxin-induced experimental shock were studied in rats. Experimental shock was induced by a single intravenous injection of endotoxin at a dose of $100 \mathrm{mg} / \mathrm{kg}$. After the injection, systolic blood pressure was reduced and heart rate was increased. Activities of serum lysosomal enzymes, such as acid phosphatase, $\beta$-glucuronidase, and cathepsin B, were increased. Serum thiobarbituric acid-reactive substances, which are important and damaging products of free radical lipid peroxidation, were significantly increased. These changes were most remarkable at $45 \mathrm{~min}$ after the injection of endotoxin. By the subcutaneous injection of SOD $(50 \mathrm{mg} / \mathrm{kg}) 12$ and $1 \mathrm{~h}$ before the administration of endotoxin $(100 \mathrm{mg} / \mathrm{kg})$, the reduction of systolic blood pressure and the increase in serum acid phosphatase, $\beta$-glucuronidase, and cathepsin B activities were significantly inhibited. By the subcutaneous injection of catalase $(1.0 \mathrm{mg} / \mathrm{kg}) 12$ and $1 \mathrm{~h}$ before the treatment with endotoxin, the decrease in systolic blood pressure and the increase in acid phosphatase and cathepsin B activities were significantly inhibited. These results indicate that oxygen-derived free radicals, such as superoxide and hydrogen peroxide, can affect the experimental shock states.
\end{abstract}

Key Words: shock, endotoxin, superoxide dismutase, catalase, rats

It is widely recognized that oxygen free radicals are implicated in a wide variety of in vivo biological reactions. Complete reduction of a molecule of oxygen to water requires four electrons, and in sequential univalent processes several intermediates will be encountered. These are the superoxide anion radical, hydrogen

*To whom correspondence should be addressed. 
peroxide, and the hydroxyl radical [1]. They are highly reactive molecules which can potentially damage surrounding cellular structures and subcellular organelles.

There is considerable indirect evidence supporting a role for oxygen radicals in circulatory shock. Crowell et al. [2] and Cunningham and Keaveny [3] reported that allopurinol, a competitive inhibitor of xanthine oxidase, substantially increased the survival rate of dogs subjected to hemorrhagic shock. The protective activity of enzymatic scavengers, such as superoxide dismutase (SOD), catalase, and glutathione peroxidase, is diminished by acidosis [4] and by endotoxin [5]. It was reported that an exposure to endotoxin can prime neutrophils for increasing their release of superoxide [6] and that an exposure to endotoxin may ultimately result in death [7].

Therefore it is evident that in every kind of shock many coexisting mechanisms may lead to the overproduction of oxygen free radicals and that a pathogenetic role of such radicals may be considered highly probable [8]. The generation of oxygen free radicals seems to be implicated in the pathogenesis of shock.

To explore this hypothesis, we examined the effects of SOD and catalase on endotoxin shock in rats.

\section{MATERIALS AND METHODS}

The animals used in the present study were female rats (200-220 g) of the Wistar strain obtained from Keari Co., Ltd., Osaka. Housing conditions consisted of 12-h lighting, controlled temperature $\left(21 \pm 3^{\circ} \mathrm{C}\right)$, and free access of feed (Oriental Yeast Co., Ltd., Tokyo) and water. Endotoxin (Escherichia coli 055: B5 lipopolysaccharide B; Difco Lab., Detroit, Michigan) was dissolved in pyrogen-free physiological saline before every experiment. Experimental shock was induced by a single injection of $100 \mathrm{mg} / \mathrm{kg}$ of endotoxin, diluted in $1.0 \mathrm{ml}$ of physiological saline, into the femoral vein.

For examination of the effects of SOD and catalase on the experimental shock, the rats were injected subcutaneously with SOD from bovine blood $(3,050 \mathrm{U} / \mathrm{mg}$ protein, Sigma Chemical Co., St. Louis, Mo.) at 10.0 or $50.0 \mathrm{mg} / \mathrm{kg}$ or catalase from bovine liver (40,000 Sigma U/mg protein, Sigma Chemical Co., St. Louis, Mo.) at 0.1 or $1.0 \mathrm{mg} / \mathrm{kg} 12$ and $1 \mathrm{~h}$ before the injection of endotoxin $(100 \mathrm{mg} / \mathrm{kg})$. Partially inactivated SOD was prepared by heating at $100^{\circ} \mathrm{C}$ for $30 \mathrm{~min}$.

Systolic blood pressure and heart rate count were measured by a tail-cuff method [9] using a sphygmomanometer PS-100 (Riken Kaihatsu Co., Tokyo). Serum acid phosphatase activity was assayed according to the method of Andersch and Szczypinski [10] using $p$-nitrophenylphosphate as a substrate. Serum $\beta$ glucuronidase activity was measured with Sigma reagents (Sigma Chemical Co., St. Louis, Mo.), based essentially on the method of Fishman et al. [11], in which phenolphthalein glucuronic acid was used as a substrate. Cathepsin B was assayed by the method of Otto and Bhakdi [12] using $\alpha$-N-benzoyl-DL-arginine-4nitro anilide as a substrate. Thiobarbituric acid (TBA)-reactive substances in 
serum were determined by the method of Yagi [13]. The serum was treated with phosphotungstic acid and reacted with thiobarbituric acid. The reaction products were measured fluorometrically with excitation at $515 \mathrm{~nm}$ and emission at 553 $\mathrm{nm}$. The concentration of TBA-reactive substances was expressed in terms of malondialdehyde $(\mathrm{nmol} / \mathrm{ml})$ using tetramethoxypropane as a standard.

\section{RESULTS}

Endotoxin-induced shock. Immediately after the injection of endotoxin, systolic blood pressure was reduced and heart rate was increased (Fig. 1). Acid phosphatase and $\beta$-glucuronidase activities were increased (Fig. 2). These changes were most remarkable at $45 \mathrm{~min}$ after the injection of endotoxin. Therefore, for

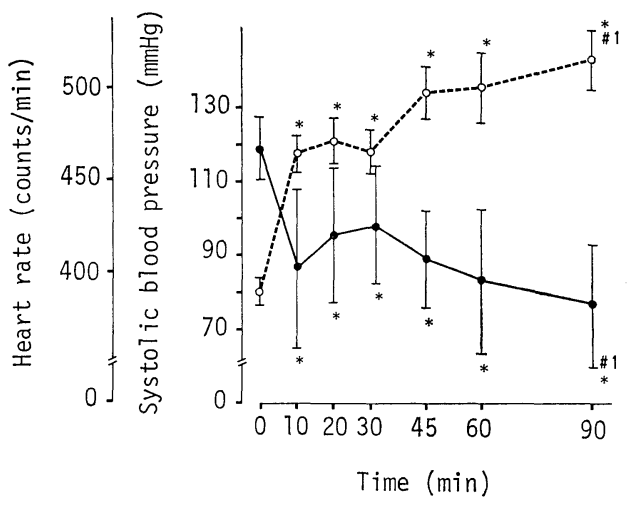

Fig. 1. Changes in systolic blood pressure and heart rate of rats injected with endotoxin $(100 \mathrm{mg} / \mathrm{kg})$. Solid circles, blood pressure; open circles, heart rate. Mean $\pm \mathrm{SD}(n=12)$. Significance between the value at 0 time and each value after injection is shown. ${ }^{*} p<0.005$.

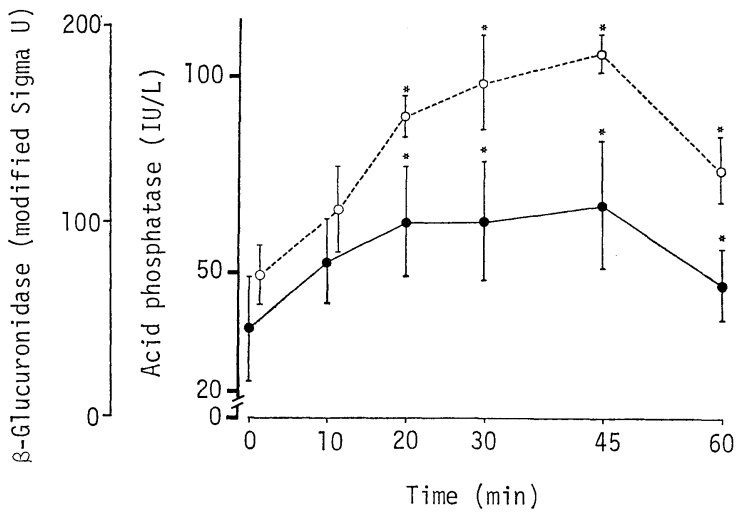

Fig. 2. Changes in serum acid phosphatase and $\beta$-glucuronidase activities after the injection of endotoxin $(100 \mathrm{mg} / \mathrm{kg})$. Solid circles, activity of acid phosphatase; open circles, that of $\beta$-glucuronidase. Mean $\pm \mathrm{SD}(n=12)$. ${ }^{*} p<0.001$. 
Table 1. Effects of SOD and catalase on experimental shock in rats.

\begin{tabular}{lccccccc}
\hline & $\begin{array}{c}\text { Blood } \\
\text { pressure } \\
(\mathrm{mmHg})\end{array}$ & $\begin{array}{c}\text { Heart rate } \\
(\text { count/min) }\end{array}$ & $\begin{array}{c}\text { Acid } \\
\text { phosphatase } \\
(\mathrm{IU} / \mathrm{liter})\end{array}$ & $\begin{array}{c}\beta \text {-glucuro- } \\
\text { nidase } \\
(\mathrm{U} / \mathrm{ml})\end{array}$ & $\begin{array}{c}\text { Cathepsin B } \\
(\mathrm{OD} / \mathrm{ml})\end{array}$ & $\begin{array}{c}\text { TBA } \\
\text { reactants } \\
(\mathrm{nmol} / \mathrm{ml})\end{array}$ & $\mathrm{Na}^{\mathrm{Na}}$ \\
\hline $\begin{array}{l}\text { Controlb } \\
\text { SOD c }\end{array}$ & $71 \pm 15$ & $490 \pm 35$ & $68.5 \pm 11.7$ & $181 \pm 71$ & $3.1 \pm 0.5$ & $3.6 \pm 0.3$ & 16 \\
$\quad 10 \mathrm{mg} / \mathrm{kg}$ & $101 \pm 15^{* *}$ & $477 \pm 43$ & $56.8 \pm 6.7^{* *}$ & $201 \pm 59$ & $2.9 \pm 0.8$ & $3.3 \pm 0.4^{*}$ & 8 \\
50 & $101 \pm 12^{* *}$ & $486 \pm 45$ & $48.4 \pm 6.8^{* *}$ & $84 \pm 23^{* *}$ & $2.1 \pm 0.5^{* *}$ & $3.2 \pm 0.2^{* *}$ & 8 \\
Catalasec & & & & & & & \\
$\quad 0.1 \mathrm{mg} / \mathrm{kg}$ & $79 \pm 21$ & $445 \pm 55^{*}$ & $55.1 \pm 8.4^{*}$ & $150 \pm 64$ & $2.8 \pm 0.7$ & $3.4 \pm 0.5$ & 8 \\
1.0 & $105 \pm 18^{* *}$ & $457 \pm 46^{*}$ & $45.1 \pm 6.7^{* *}$ & $165 \pm 59$ & $2.1 \pm 0.4^{* *}$ & $3.5 \pm 0.3$ & 12 \\
Normal ratsd & $121 \pm 11^{* *}$ & $404 \pm 29^{* *}$ & $36.7 \pm 8.4^{* *}$ & $58 \pm 18^{* *}$ & $2.3 \pm 0.4^{* *}$ & $2.9 \pm 0.3^{* *}$ & 14 \\
\hline
\end{tabular}

Results are expressed as mean value \pm SD. a Number of rats used. b Physiological saline $(1.0 \mathrm{ml})$ was injected s.c. 12 and $1 \mathrm{~h}$ before the injection of endotoxin $(100 \mathrm{mg} / \mathrm{kg})$. c SOD or catalase was dissolved in physiological saline, and injected subcutaneously 12 and $1 \mathrm{~h}$ before the administration of endotoxin $(100 \mathrm{mg} / \mathrm{kg})$. d Normal rats were injected with 1.0 $\mathrm{ml}$ of physiological saline alone. ${ }^{*} p<0.01,{ }^{* *} p<0.001$ for difference from the value of control rats by Student's t-test.

examination of the protective effects of SOD and catalase on experimental shock, all rats were killed at 45 min after the endotoxin injection.

Effects of SOD and catalase on systolic blood pressure and heart rate. Systolic blood pressure of rats injected with $1.0 \mathrm{ml}$ of physiological saline alone was $121 \pm 11$ $\mathrm{mmHg}$ (mean $\pm \mathrm{SD}$ ). The blood pressure was reduced significantly $45 \mathrm{~min}$ after the injection of endotoxin. However, this reduction was significantly inhibited by 10 or $50 \mathrm{mg} / \mathrm{kg}$ of SOD, or by $1.0 \mathrm{mg} / \mathrm{kg}$ of catalase (Table 1 ).

Heart rate was increased significantly by the injection of endotoxin. The increase was inhibited by the prior administration of 0.1 or $1.0 \mathrm{mg} / \mathrm{kg}$ of catalase, but not by that of SOD (Table 1).

Changes in activities of serum acid phosphatase, $\beta$-glucuronidase, and cathepsin $B$. Serum acid phosphatase activity was increased $45 \mathrm{~min}$ after the injection of endotoxin. The increase in the activity was inhibited significantly by the administration of SOD (10 or $50 \mathrm{mg} / \mathrm{kg}$ ) or catalase $(0.1$ or $1.0 \mathrm{mg} / \mathrm{kg}$ ) (Table 1).

Serum $\beta$-glucuronidase activity was also increased significantly after the injection of endotoxin. This increase was inhibited by the pretreatment with $50 \mathrm{mg} / \mathrm{kg}$ of SOD, but was unaffected by catalase (Table 1).

Serum levels of cathepsin B were increased significantly after the injection of endotoxin. The increase in the level was inhibited by the prior administration of $50 \mathrm{mg} / \mathrm{kg}$ of SOD or $1.0 \mathrm{mg} / \mathrm{kg}$ of catalase (Table 1 ).

Changes in TBA reactants. Serum TBA reactants were increased significantly $45 \mathrm{~min}$ after the injection of endotoxin. The increase was inhibited by the administration of SOD, but not by catalase.

Effect of heat-denatured SOD on shock. SOD was partially inactivated by heating. The heat denatured SOD did not show any protective effect on endotoxininduced shock states. 


\section{DISCUSSION}

The present study has demonstrated the protective effects of SOD and catalase against the aggravation of shock in rats induced by endotoxin. These findings suggest that superoxide and hydrogen peroxide can affect the status of experimental shock.

Novelli and De Gaudio suggested the implication of oxygen free radicals in the pathogenesis of shock states [8]. The generation of radicals is increased in some critical states directly related to shock such as tissue hypoxia $[14,15]$, incomplete ischemia and tissue reperfusion [16], activation of the arachidonic acid cascade [17], and complement-induced granulocyte aggregation [18].

Gray reported that SOD enhances survival of endotoxin-challenged mice [7]. These observations support the hypothesis that oxygen radicals can be produced in endotoxin shock.

In the present investigation, serum TBA-reactive substances, which are important and damaging products of free radical lipid peroxidation, were increased after the endotoxin treatment. Previously we reported that the levels of TBA reactants in serum, abdominal aortic wall, and ileum mucosa were increased in experimental disseminated intravascular coagulation in rats induced by endotoxin [19]. In shock states, peroxidation may occur in several organs, and lipid peroxides produced by radicals may aggravate these pathological conditions.

Endotoxin has many biological effects. Hydrogen peroxide is released from macrophages activated by endotoxin [20]. In addition, endotoxin activates the complement system, producing $\mathrm{C} 3 \mathrm{a}$ and $\mathrm{C} 5 \mathrm{a}$. Stimulated by these complement components, polymorphonuclear leukocytes generate significant amounts of superoxide anion [21]. These active oxygens produced by endotoxin may play an important role in determining the degree of shock. Since SOD and catalase are effective against shock, these enzymes may be useful for the treatment of these pathological conditions accompanying the shock state.

\section{REFERENCES}

1. Fridovich, I. (1973): The biology of oxygen radicals. Science, 201, 875-880.

2. Crowell, J.W., Jones, C.E., and Smith, E.E. (1969): Effect of allopurinol on hemorrhagic shock. Am. J. Physiol., 216, 744-748.

3. Cunningham, S.K., and Keaveny, T.V. (1978): Effect of a xanthine oxidase inhibitor on adenine nucleotide degradation in hemorrhagic shock. Eur. Surg. Res., 10, 305-313.

4. Bielski, B.H.J., and Allen, A.O. (1977): Mechanism of disproportionation of superoxide radicals. J. Physiol. Chem., 81, 1048-1052.

5. Ogawa, R., Morita, T., Kunimoto, F., and Fujita, T. (1982): Changes in hepatic lipoperoxide concentration in endotoxemic rats. Circ. Shock, 9, 369-374.

6. Johnston, R.B., Jr., Guthrie, L.A., and McPhail, L.C. (1983): Priming of neutrophils for enhanced oxidative metabolism by bacterial endotoxin, in Oxy Radicals and Their Scavenger

Vol. 1, No. 2, 1986 
Systems. Vol. II, Cellular and Medical Aspects, ed. by Greenwald, R.A., and Cohen, G., Elsevier Science Publishing Co., Inc., New York, pp. 69-73.

7. Gray, B. (1981): Effects of superoxide dismutase of lipopolysaccharide-stressed mice and alteration of lung enzyme levels by endotoxin. Toxicol. Appl. Pharmacol., 60, 479-484.

8. Novelli, G.P., and De Gaudio, A.R. (1983): Oxygen free-radicals in shock states, in Shock Research, ed. by Lewis, D.H., and Haglund, U., Elsevier Science Publishers B.V., Amsterdam, pp. 31-42.

9. Bunag, R. (1973): Validation in awake rats of a tail-cuff method for measuring systolic pressure. J. Appl. Physiol., 34, 279-282.

10. Andersch, M.A., and Szczypinski, A.J. (1947): Use of $p$-nitrophenylphosphate as the substrate in determination of acid phosphatase. Am. J. Clin. Path., 17, 571-574.

11. Fishman, W.H., Kato, K., Anstiss, C.L., and Green, S. (1967): Human serum $\beta$-glucuronidase; its measurement and some of its properties. Clin. Chim. Acta, 15, 435-447.

12. Otto, K., and Bhakdi, S. (1969): Zur Kenntnis des Kathepsins B: Spezifitat und Eigenschften. Hoppe-Seyler's Z. Physiol. Chem., 350, 1577-1588.

13. Yagi, K. (1976): A simple fluorometric assay for lipid peroxide in blood plasma. Biochem. Med., 15, 212-216.

14. Yoshikawa, T., Furukawa, Y., Wakamatsu, Y., Takemura, S., Tanaka, H., and Kondo, M. (1982): Experimental hypoxia and lipid peroxide in rats. Biochem. Med., 27, 207-213.

15. Demopoulos, H.B., Flamm, E.S., Pietronigro, D.D., and Seligman, M.L. (1980): Free radical pathology and the microcirculation in the major central nervous system disorders. Acta Physiol. Scand. Suppl., 492, 43-57.

16. Del Maestro, R.F., Thaw, H.H., Biork, J., Planker, M., and Arfors, K.E. (1980): Free radicals as mediators of tissue injury. Acta Physiol. Scand. Suppl., 492, 43-57.

17. Lefer, A.M., Araki, H., and Okamatsu, S. (1981): Beneficial actions of a free radical scavenger in traumatic shock and myocardial ischemia. Circ. Shock, 8, 273-282.

18. Goldstein, I.M., Roos, D., Kaplan, H.B., and Weissman, G. (1975): Complement and immunoglobulins stimulate superoxide production by human leukocytes independently of phagocytosis. J. Clin. Invest., 56, 1155-1163.

19. Yoshikawa, Y., Murakami, M., Furukawa, Y., Kato, H., Takemura, S., and Kondo, M. (1983): Lipid peroxidation and experimental disseminated intravascular coagulation in rats induced by endotoxin. Thromb. Haemostas., 49, 214-216.

20. Kato, H., Yaoita, H., Saito-Taki, T., and Nakano, M. (1984): LPS-induced hydrogen peroxide release from peritoneal macrophages of normal and immunodefective mice, in Immunopharmacology of Endotoxicosis, ed. by Agarwal, M.K., and Yoshida, M., Walter de Gruyter \& Co., Berlin, pp. 21-37.

21. Goldstein, I.M., Cerqueira, M., Lind, S., and Kaplan, H.B. (1977): Evidence that the superoxide-generating system of human leukocytes is associated with cell surface. J. Clin. Invest., 59, 249-254. 